\title{
Qual o Custo Governamental do Seguro Agrícola?
}

\author{
Vitor Augusto Ozaki ${ }^{1,2}$
}

Resumo: Para 2011, estavam previstos R 570 milhões ao Programa de Subvenção ao Prêmio do Seguro Rural (PSR), mas apenas R\$ 253,4 milhões foram alocados ao Programa em função de contingenciamentos do governo. Apesar disso, foi possível segurar 5,6 milhões de hectares com uma importância segurada de R\$ 7,3 bilhões. Mas qual deveria ser o volume de recursos direcionados ao PSR para que todo o crédito de custeio das lavouras pudesse ser coberto pelo mercado segurador? O estudo apresenta uma metodologia para calcular qual deve ser o valor orçamentário médio do PSR para cobrir cem por cento do custeio das lavouras. Para 2011, os resultados sugerem que o volume de recursos deveria ter sido quatro vezes maior do que o valor empenhado. Ademais, os resultados foram desagregados por estado e por culturas agrícolas. A importância do PSR para a massificação do seguro rural é indiscutível. Porém, além dos recursos do PSR estarem subdimensionados, outro problema ameaça a continuidade do Programa. Pelo terceiro ano consecutivo, o PSR tem sofrido graves contingenciamentos que têm impactado negativamente o mercado. Portanto, fica evidente a necessidade de maior esforço do governo federal em ampliar os recursos da subvenção e destiná-los única e integralmente ao PSR.

Palavras-chaves: seguro rural, política agrícola, ARIMA, crédito rural.

Abstract: In 2011, 570 million reais were estimated to be used in the Crop Insurance Premium Subsidy (PSR), but only 253.4 million reais was allocated to the Program. In spite of this fact, it was possible to insure 5.6 million hectares with a liability of 7.3 billion reais. In this context, what should be the amount of resources to the PSR in order to cover the total amount of rural credit by the insurance market? The study presents a methodology to calculate, on average, what should be the budget of the PSR to insure the rural credit. The results suggest that the amount of resources should have been four times greater than the committed value. Moreover, the results were divided by state and crop. The PSR plays an important role to the development of the crop insurance in Brazil. However, two problems remain unsolved: the budget is far beyond the desirable and it has been restricted

1 Professor Associado do Dept. de Economia, Administração e Sociologia da ESALQ/USP e coordenador do Grupo Geser (Gestão em Seguros e Riscos). E-mail: vitorozaki@usp.br

2 O autor agradece à Fapesp (Fundação de Amparo à Pesquisa do Estado de São Paulo) pelo suporte financeiro desta pesquisa. 
over the last three years. Therefore, there is an evident need for greater commitment from the Brazilian government to expand the resources of the PSR and direct it unique and fully to the PSR.

Key-words: crop insurance, agricultural policy, ARIMA, rural credit.

Classificação JEL: Q19.

\section{Introdução}

O desenvolvimento de um mercado de seguro rural privado é uma reivindicação relativamente antiga do setor agropecuário. Ao longo dos anos, diversas seguradoras ofertaram o seguro rural, mas as coberturas eram restritas e a abrangência, limitada (OZAKI, 2008).

Esse panorama mudou com a sanção da Lei n. 10.823, de 2003, que, dentre outras atribuições, criou o Programa de Subvenção ao Prêmio do Seguro Rural (PSR). Com essa medida, o governo estabeleceu as bases para o início da massificação do seguro rural, na medida em que reduziu o preço do seguro pago pelos produtores rurais (ALMEIDA, 2007; RAMOS, 2009).

Desde o início do Programa, em 2005, muitos produtores tiveram acesso ao seguro rural. Desse período até 2011, a área segurada cresceu de 68,1 mil hectares para 5,6 milhões (MAPA, 2012). De forma geral, seu funcionamento consiste em estabelecer percentuais de subvenção por modalidade de seguro e tipo de cultura. Esse percentual corresponde à responsabilidade assumida pelo governo. Por exemplo, se o prêmio total a ser pago para segurar uma lavoura de soja for igual a $\mathrm{R} \$ 100$ mil e o percentual, igual a $50 \%$, o produtor deverá pagar R\$ 50 mil, e o governo federal, o restante do prêmio.
O montante alocado ao Programa é orçado um ano antes de sua utilização, de acordo com a Lei Orçamentária Anual (LOA). Vale destacar que as estimativas de aporte de recursos orçamentários são definidas no Plano Trienal do Seguro Rural (Quadro 1).

A experiência internacional mostra que o desenvolvimento do seguro rural está, muitas vezes, associado à participação do governo, na forma de programas de subvenção. Em países com seguro rural desenvolvido, o governo aloca uma grande quantidade de recursos para a subvenção dos prêmios.

Nos EUA, por exemplo, o total gasto em subvenção em 2011 foi da ordem de US\$ 7,5 bilhões (USDA/RMA, 2012). Na Espanha, o total alocado à subvenção foi de US\$ 513 milhões. Para se ter uma noção mais precisa da participação do governo no mercado de seguros, a Figura 1 mostra a relação entre o total subvencionado e o capital segurado para os EUA, Espanha e Brasil.

A Figura 1 mostra a participação efetiva do governo no mercado segurador. $\mathrm{O}$ indicador revela qual a participação do governo no total segurado pelo mercado. Nota-se que, nos últimos cinco anos, o governo norte-americano apresentou um índice de subvenção médio de 6\% em relação ao capital segurado total, enquanto o índice de subvenção do governo espanhol foi,

Quadro 1. Estimativa de aporte de recursos orçamentários, nos triênios 2007-2009 e 2010-2012, em milhões de reais

\begin{tabular}{cccccc}
\hline $\mathbf{2 0 0 7}$ & $\mathbf{2 0 0 8}$ & $\mathbf{2 0 0 9}$ & $\mathbf{2 0 1 0}$ & $\mathbf{2 0 1 1}$ & $\mathbf{2 0 1 2}$ \\
\hline 100 & 176 & 176 & 451 & 570 & 680 \\
\hline
\end{tabular}

Fonte: Mapa (2012). 
Figura 1. Relação entre subvenção e capital segurado, nos EUA, Espanha e Brasil, de 2006 a 2011

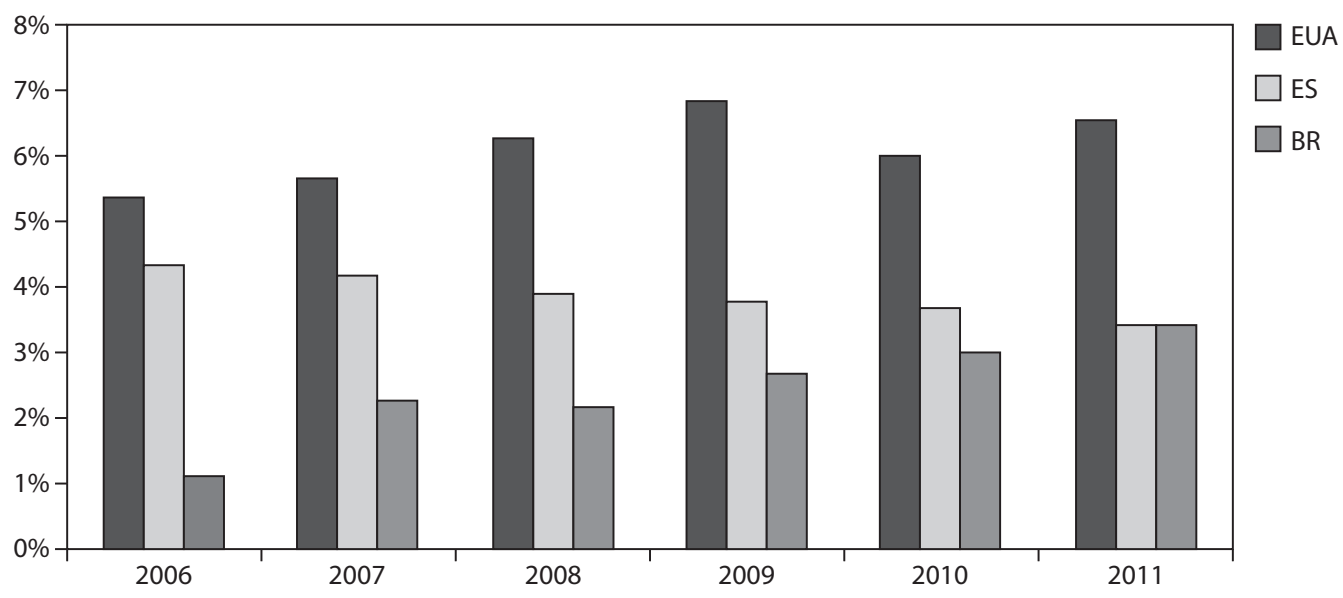

Fonte: EUA - USDA/RMA (2012); Espanha - Agroseguro (2012); Brasil - Mapa (2012).

em média, igual a $4 \%$. Embora os dois países apresentem um índice superior ao brasileiro, com média de $2,4 \%$, esse percentual tem aumentado ao longo dos anos. De 2006 até 2011, a relação da subvenção sobre o capital segurado aumentou de pouco mais de $1 \%$ para quase $3,5 \%$, igualando-se ao percentual espanhol.

Isso mostra que, comparativamente a outros países que têm seguro rural desenvolvido, o Brasil pode aumentar seu índice de subvenção e, além disso, estabelecer patamares superiores aos apresentados no Plano Trienal. O problema consiste em se determinar o nível de subvenção adequado ao mercado brasileiro. Em outras palavras, qual o patamar de subvenção necessário para cobrir todo o crédito rural de custeio para lavouras?

Possivelmente, levando-se em conta a dimensão territorial, espera-se que o total de subvenção seja próximo ao utilizado pelo programa de seguro agrícola norte-americano (US\$ 7,5 bilhões), mas não é possível comparar o programa norte-americano com o brasileiro em virtude de suas respectivas diferenças. Lá, existe uma extensa gama de produtos e uma ampla variedade de culturas cobertas, além de um orçamento muito maior do que o caso brasileiro.

Nesse contexto, o artigo pretende abordar a questão orçamentária do PSR com o objetivo de estabelecer quais seriam os valores adequados de subvenção para atender a crescente demanda pelo seguro agrícola. O objetivo é definir quanto o governo deveria ter investido para assegurar todo o crédito de custeio agrícola de lavouras nos anos de 2005 a 2011, e prever quais seriam esses valores em 2012 e 2013. Os resultados serão apresentados para o Brasil e desagregados por cultura e por estado.

O artigo está dividido em seis seções: a primeira contextualiza o seguro rural, destaca o problema e define os objetivos. A segunda seção revela os antecedentes do PSR e seu panorama atual, a terceira descreve a metodologia. A quarta seção mostra a fonte dos dados e discute os resultados e, por fim, a última seção conclui o artigo.

\section{Antecedentes e panorama atual do programa de subvenção ao Prêmio do Seguro Rural}

O Programa de Subvenção ao Prêmio do Seguro Rural teve início em 2005. Nessa época, o seguro rural privado passava por momentos de instabilidade, já que a carteira agrícola da Companhia de Seguros do Estado de São Paulo (Cosesp), principal seguradora no ramo rural, 
Figura 2. Evolução da área segurada subvencionada, em milhões de hectares, e do percentual da área segurada sobre a área plantada, de 2005 a 2011

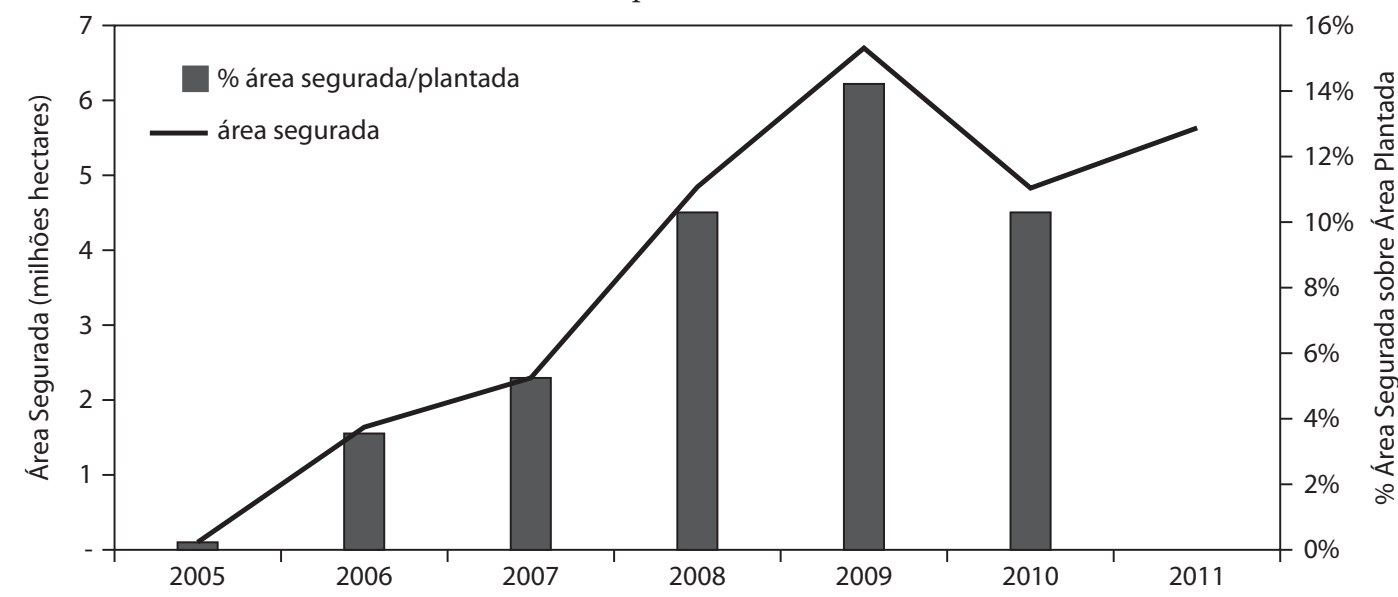

Fonte: Mapa (2012) e IBGE (2012).

passava por uma drástica redução em função do seu processo de privatização.

Com a saída eminente da Cosesp, o seguro rural passou a ser ofertado pelas seguradoras Vera Cruz, Aliança do Brasil, Minas Brasil e Seguradora Brasileira Rural (SBR). Desde 2005 até 2009, o seguro rural apresentou relativo crescimento. Em 2005, a área coberta pelo PSR foi de aproximadamente 68 mil hectares. Passados seis anos, a área coberta pelo seguro rural subvencionado foi de quase 5,6 milhões de hectares (Figura 2).

A Figura 2 apresenta duas informações importantes: i) a evolução da área segurada, em milhões de hectares (eixo vertical da esquerda - linha preta); e ii) a evolução do percentual da área segurada sobre a área plantada total com as respectivas culturas seguradas.
Até 2009, a área segurada aumentou continuamente, atingindo 6,7 milhões de hectares. Em 2010, houve redução significativa principalmente em função de cortes no orçamento do PSR (Tabela 1). Em 2011, a área segurada voltou a crescer em razão do aumento dos recursos alocados ao PSR.

Os dados sugerem que há uma correlação positiva entre orçamento do PSR e área segurada. Em outras palavras, quanto maior o montante de recursos alocados ao Programa, maior será a área segurada. Além disso, a Figura 2 mostra que, desde o início do Programa, a área segurada não ultrapassou $15 \%$ da área total plantada pelas respectivas culturas seguradas. Considerando-se a área plantada por todas as culturas permanentes e temporárias, de acordo com a classificação do IBGE, a área segurada máxima não superou $10 \%$ do total.

Tabela 1. Evolução do número de apólices, importância segurada, prêmio total, subvenção total, de 2005 a 2011

\begin{tabular}{ccccc}
\hline Ano & Apólices & Importância Segurada (R\$) & Prêmio Total (R\$) & Subvenção Total (R\$) \\
\hline 2005 & 849 & 126.637 .756 & 8.684 .371 & 2.314 .919 \\
2006 & 21.779 & 2.869 .325 .775 & 71.119 .010 & 31.121 .860 \\
2007 & 31.637 & 2.706 .036 .106 & 127.741 .171 & 60.961 .993 \\
2008 & 60.120 & 7.209 .176 .952 & 324.744 .319 & 157.544 .955 \\
2009 & 74.166 & 9.683 .880 .227 & 477.785 .804 & 259.610 .963 \\
2010 & 52.880 & 6.541 .634 .782 & 368.169 .102 & 198.277 .601 \\
2011 & 57.885 & 7.339 .468 .651 & 466.393 .329 & 253.451 .980 \\
\hline
\end{tabular}

Fonte: Mapa (2012). 
Pela Tabela 1 observa-se que, além da área segurada, o número de apólices, a importância segurada e o prêmio total aumentam em função da elevação dos recursos direcionados ao PSR. Isso porque, quanto maior seu orçamento, mais produtores terão acesso ao seguro e, consequentemente, maior será a importância segurada e também a arrecadação de prêmios.

Em 2011, o orçamento alocado ao PSR cresceu $22 \%$ em relação a 2010, mas foi inferior ao orçamento de 2009. Em 2011, as culturas enquadradas como grãos (soja, trigo, milho - verão e inverno, arroz, outros) foram responsáveis por quase $80 \%$ da área segurada total, quase $65 \%$ dos recursos da subvenção, $67 \%$ do total de prêmios arrecadados, além de $63 \%$ de toda a importância segurada.

Nota-se, portanto, que essas culturas são as mais importantes no PSR. A soja ocupa um lugar de destaque. As lavouras de soja foram responsáveis por 38\% da importância segurada e dos prêmios totais, $48 \%$ da área segurada total e 35\% dos recursos da subvenção. Em relação à concentração regional do PSR, em 2011, a região Sul foi a mais importante no PSR, representando 61\% dos recursos do Programa. Em seguida, aparecem as regiões Sudeste e Centro-Oeste com, respectivamente, 18 e 17\% (MAPA, 2012).

\section{Metodologia}

\subsection{Cálculo do montante máximo de subvenção}

Para se determinar o valor máximo de subvenção é necessário antes entender o funcionamento do seguro agrícola de custeio. Esse tipo de contrato tem por objetivo cobrir reduções na produtividade causadas por eventos climáticos adversos. A indenização I para cada propriedade $i$ pode ser expressa da seguinte forma (OZAKI, 2012):

$$
\mathrm{I}_{\mathrm{i}}=\left\{\max \left[\left(\mathrm{y}_{\mathrm{i}, \mathrm{j}}^{\mathrm{c}}-\mathrm{y}_{\mathrm{i}}\right) / \mathrm{y}_{\mathrm{i}, \mathrm{j}}^{\mathrm{c}}, 0\right]\right\} \times \mathrm{L}_{\mathrm{i}}
$$

Em que:

$\mathrm{y}_{\mathrm{i}, \mathrm{j}}^{\mathrm{c}}$ é a produtividade garantida;

$\mathrm{y}_{\mathrm{i}}$ é a produtividade observada;

L é o limite máximo de indenização ou garantia;

A produtividade garantida é descrita de acordo com a equação: $y_{i, j}^{c}=\alpha_{i} \mu_{j}$. Em que $\alpha$ é o nível de cobertura escolhida pelo produtor para a propriedade $i, 0<\alpha<1$, e $\mu$ é a produtividade esperada do município $j$. Ao longo da safra, se a produtividade na propriedade segurada $y_{i}$ for menor do que a produtividade garantida, então o produtor é indenizado.

Alguns contratos diferem da forma básica, pelo acréscimo de algumas variáveis, tais como, percentualredutor-paracálculoda produtividade garantida ajustada - e o percentual de despesas para despesas previstas no plano de custeio. No estudo, essas variáveis são consideradas iguais a zero. Em geral, $L$ é o custeio da cultura.

Por sua vez, o prêmio $P$ é determinado pela multiplicação da taxa de prêmio $\pi$ por $L$ :

$$
\mathrm{P}_{\mathrm{i}, \mathrm{j}}=\pi_{\mathrm{j}} \times \mathrm{L}_{\mathrm{i}, \mathrm{j}}
$$

Normalmente, a taxa de prêmio é municipalizada em virtude de se utilizar a base de produtividade agrícola municipal do IBGE para o cálculo da taxa de prêmio. Porém, o prêmio total é pago individualmente, de acordo com o limite máximo de indenização de cada propriedade $i$ localizado no município $j$. Uma vez que o prêmio foi determinado, o valor da subvenção é calculado dependendo da modalidade de seguro, e também, do tipo de cultura, se considerada a modalidade agrícola.

Como o objetivo do estudo não é determinar a subvenção por propriedade rural, mas equacionar o problema orçamentário do PSR, em nível macro, serão considerados valores agregados para $\pi \mathrm{e}$ também para $L$. Nesse contexto, a taxa de prêmio será a média praticada pelo mercado para cada um dos anos considerados e para todas as culturas, que será calculada pela divisão entre prêmio total e importância segurada, enquanto o limite máximo de indenização será o crédito de custeio 
de lavouras enquadrado no Sistema Nacional de Crédito Rural (SNCR). O prêmio médio total será, então, a multiplicação da taxa média pelo custeio total de lavouras para cada um dos anos.

Para o cálculo do montante de subvenção, considera-se o percentual do valor subvencionado em relação ao prêmio total para cada um dos anos. Ou seja, dividindo-se o total gasto com a subvenção pelo total de prêmios arrecadados pelo mercado para todas as modalidades, multiplicado por cem, obtêm-se o percentual de subvenção, que é posteriomente multiplicado pelo valor médio do prêmio, resultando em um valor médio da subvenção para cada ano.

\subsection{Modelo de previsão}

No estudo, optou-se por utilizar o modelo não estacionário ARIMA $(\mathrm{p}, \mathrm{d}, \mathrm{q})$ para realizar as previsões do volume de crédito de custeio dois passos à frente e, posteriormente, calcular o montante de subvenção com base nas previsões. De forma geral, pode-se descrever um modelo estacionário ARMA $(p, q)$ da seguinte forma:

$$
\begin{aligned}
& Y_{t}=\mu+\phi_{1} Y_{t-1}+\ldots+\phi_{p} Y_{t-p}+ \\
& +\alpha_{t}-\theta_{1} \alpha_{t-1}-\ldots-\theta_{q} \alpha_{t-q}
\end{aligned}
$$

em que: $\alpha_{t}$ segue um processo ruído branco com média zero e variância $\sigma_{a}^{2}$, tal que: $\mathrm{E}\left(\alpha_{\mathrm{t}}\right)=0, \forall \mathrm{t}$, $\operatorname{Var}\left(\alpha_{\mathrm{t}}\right)=\sigma_{\alpha}^{2}, \forall \mathrm{t}, \mathrm{E}\left(\alpha_{\mathrm{t}} \cdot \alpha_{\mathrm{s}}\right)=0, \mathrm{~s} \neq \mathrm{t}$. Ademais, $Y$ representa a variável de custeio agrícola e $\mu$, a média do processo. Nesse caso, supõe-se que a série temporal é estacionária. Para se verificar a estacionariedade, utilizou-se o teste de raiz unitária e a função de autocorrelação (BOX et al., 2008; DICKEY e FULLER, 1979; DICKEY e FULLER, 1981; FULLER, 1976; CRYER e CHAN, 2008).

O método da máxima verossimilhança foi utilizado para estimar os parâmetros utilizando-se o software R versão 2.15.1 (R Development Core Team, 2012). O diagnóstico do ajuste foi realizado por uma inspeção nos resíduos por meio da função de autocorrelação e função de autocorrelação parcial, além do teste de Ljung e Box (LJUNG e BOX, 1978).

O critério utilizado para a escolha de modelos foi o erro absoluto médio (MAE) dado por:

$$
\mathrm{E}\left|\mathrm{Y}_{\mathrm{h}}-\hat{\mathrm{Y}}(\mathrm{h})\right|
$$

em que $Y_{h}$ é a observação de custeio $h$ passos à frente e $\hat{Y}(h)$ é a previsão do custeio $h$ passos à frente.

\section{Fonte de dados, resultados e discussão}

As variáveis utilizadas no estudo são: i) o crédito de custeio de lavoura para o período de 1994 a 2011, presentes no arquivo "rel5162" do

Figura 3. Evolução da importância segurada e do crédito de custeio, em bilhões de reais, de 2005 a 2011

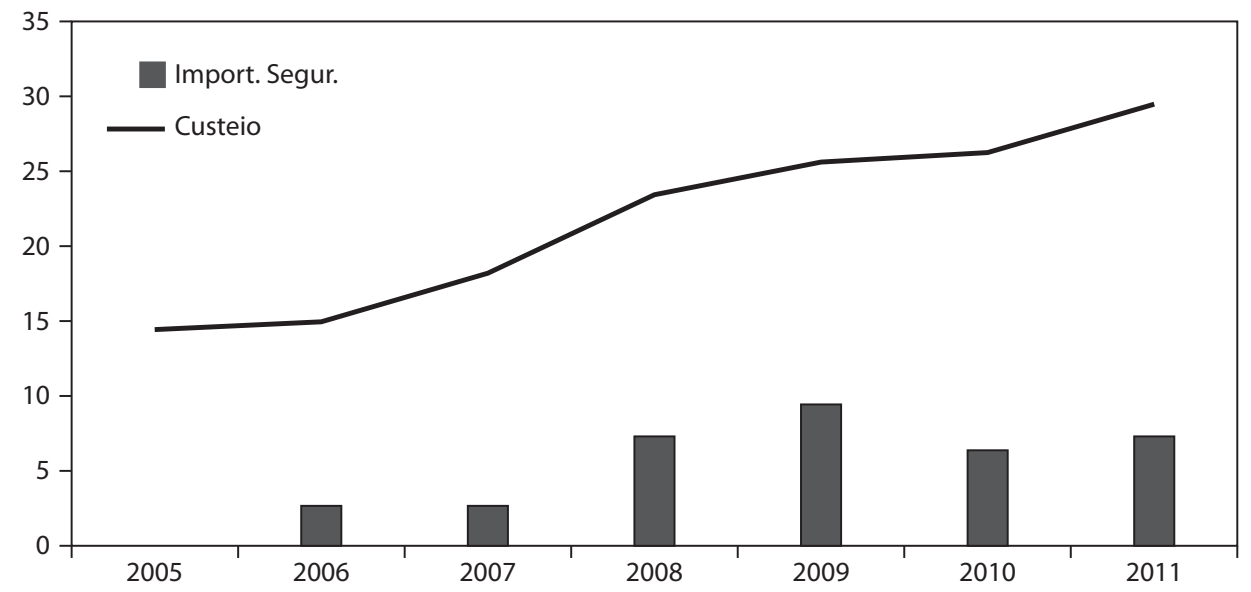

Fonte: Ministério da Agricultura, Pecuária e Abastecimento (2012) para importância segurada e Bacen (2012) para crédito de custeio. 
Figura 4. Evolução dos prêmios totais, em milhões de reais, de 2005 a 2011

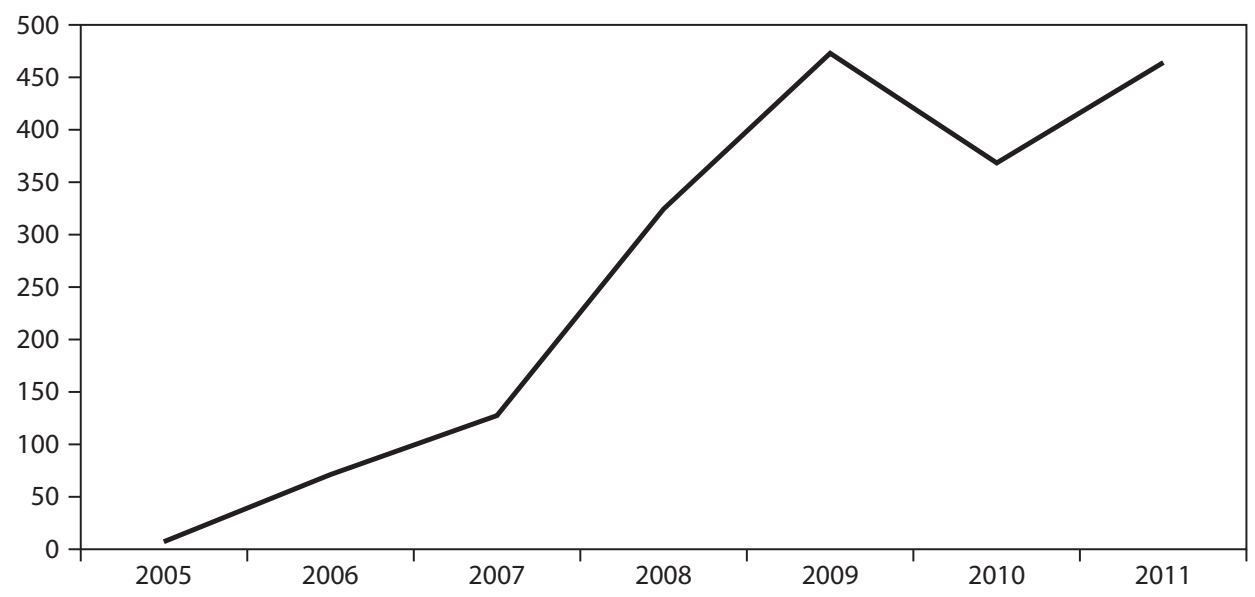

Fonte: Ministério da Agricultura, Pecuária e Abastecimento (2012).

Banco Central (BACEN, 2012); e ii) o prêmio total e importância segurada, fornecidas pelo Mapa. Para as previsões do custeio, foram utilizadas informações desde 1994. Por outro lado, para o cálculo do valor médio do prêmio e do orçamento médio do PSR, foram utilizados dados de custeio de 2005 até 2011 (Figuras 3 e 4).

A Tabela 2 mostra as taxas médias de prêmio praticadas no mercado, os valores do crédito de custeio e o valor médio do prêmio total, considerando-se que todo o crédito de custeio estivesse coberto pelo seguro agrícola. Nessa situação, o prêmio médio arrecadado pelo mercado seria aproximadamente igual a $R$ \$ 2,5 bilhões em 2011, ao invés dos R\$ 466,4 milhões (Tabela 1).

Nesse período, o percentual do prêmio subvencionado pelo governo não apresentou grande variação, com exceção de 2005 (Tabela 3). De 2006 a 2011, o valor médio do percentual de subvenção situou-se ao redor de $50 \%$. Esse percentual reflete a predominância do grupo contendo as culturas do algodão, arroz, milho e soja, que tem o percentual de subvenção definido em $50 \%$ (Tabela 4). Para ser ter uma ideia da predominância dessas culturas, em 2010 elas representaram $49,2 \%$ do total subvencionado em todo o mercado segurador.

Tabela 2. Taxa média de prêmio, custeio e valores calculados do prêmio total médio, em reais, de 2005 a 2011

\begin{tabular}{cccc}
\hline Ano & Taxa Média de Prêmio (\%) & Custeio (R\$) & Prêmio Total Médio (R\$) \\
\hline 2005 & 6,9 & 14.737 .778 .863 & 1.337 .414 .192 \\
2006 & 2,5 & 14.783 .478 .982 & 476.363 .132 \\
2007 & 4,7 & 18.538 .859 .447 & 1.148 .433 .967 \\
2008 & 4,5 & 23.575 .711 .796 & 1.431 .836 .410 \\
2009 & 4,9 & 25.619 .265 .199 & 1.633 .694 .408 \\
2010 & 5,6 & 26.581 .128 .988 & 1.937 .945 .247 \\
2011 & 6,4 & 29.437 .401 .923 & 2.518 .207 .212 \\
\hline
\end{tabular}

Fonte: Ministério da Agricultura, Pecuária e Abastecimento (2012). 
Tabela 3. Percentual do prêmio subvencionado e valor médio de subvenção, em reais, de 2005 a 2011

\begin{tabular}{ccc}
\hline & Percentual do prêmio subvencionado & Valor médio da subvenção \\
\hline 2005 & $26,7 \%$ & 269.404 .366 \\
2006 & $43,8 \%$ & 160.347 .552 \\
2007 & $47,7 \%$ & 417.646 .245 \\
2008 & $48,5 \%$ & 515.209 .223 \\
2009 & $54,3 \%$ & 686.815 .817 \\
2010 & $53,9 \%$ & 805.676 .664 \\
2011 & $54,3 \%$ & 1.016 .554 .216 \\
\hline
\end{tabular}

Fonte: Resultados da pesquisa.

Tabela 4. Percentuais de subvenção da modalidade agrícola, por cultura, no triênio 2010/2012

\begin{tabular}{lc}
\hline \multicolumn{1}{c}{ Culturas } & Subvenção (\%) \\
\hline Feijão, milho segunda safra e trigo & 70 \\
Ameixa, aveia, canola, caqui, cevada, centeio, figo, kiwi, linho, maçã, nectarina, pera, pêssego, sorgo, & 60 \\
triticale e uva & 50 \\
Algodão, arroz, milho e soja & 40 \\
Abacate, abacaxi, abóbora, abobrinha, alface, alho, amendoim, atemoia, banana, batata, berinjela, & \\
beterraba, cacau, café, caju, cana-de-açúcar, cebola, cenoura, cherimoia, chuchu, couve-flor, ervilha, & \\
escarola (chicória), fava, girassol, goiaba, graviola, jiló, laranja, lichia, lima, limão e demais cítricos, \\
mamão, mamona, mandioca, manga, maracujá, melancia, melão, morango, pepino, pimentão, \\
pinha, quiabo, repolho, sisal, tangerina, tomate, vagem e demais hortaliças e legumes
\end{tabular}

Fonte: Ministério da Agricultura, Pecuária e Abastecimento (2012).

A Tabela 3 revela ainda os valores que deveriam ser alcançados ao PSR, supondo-se que $100 \%$ do crédito de custeio estivesse segurado. Levando-se em conta esse cenário, em 2011, esse valor deveria ter sido aproximadamente igual a R\$ 1 bilhão. Em 2011, foram alocados ao PSR
$\mathrm{R} \$ 253,5$ milhões, ou seja, apenas $18 \%$ do valor orçamentário estimado.

A Figura 5 compara a subvenção real com relação à subvenção calculada. O percentual entre a subvenção real sobre a subvenção calculada apresentou tendência crescente até 2009, quanto

Figura 5. Evolução da subvenção real, calculada e percentual da subvenção real sobre a calculada, de 2005 a 2011

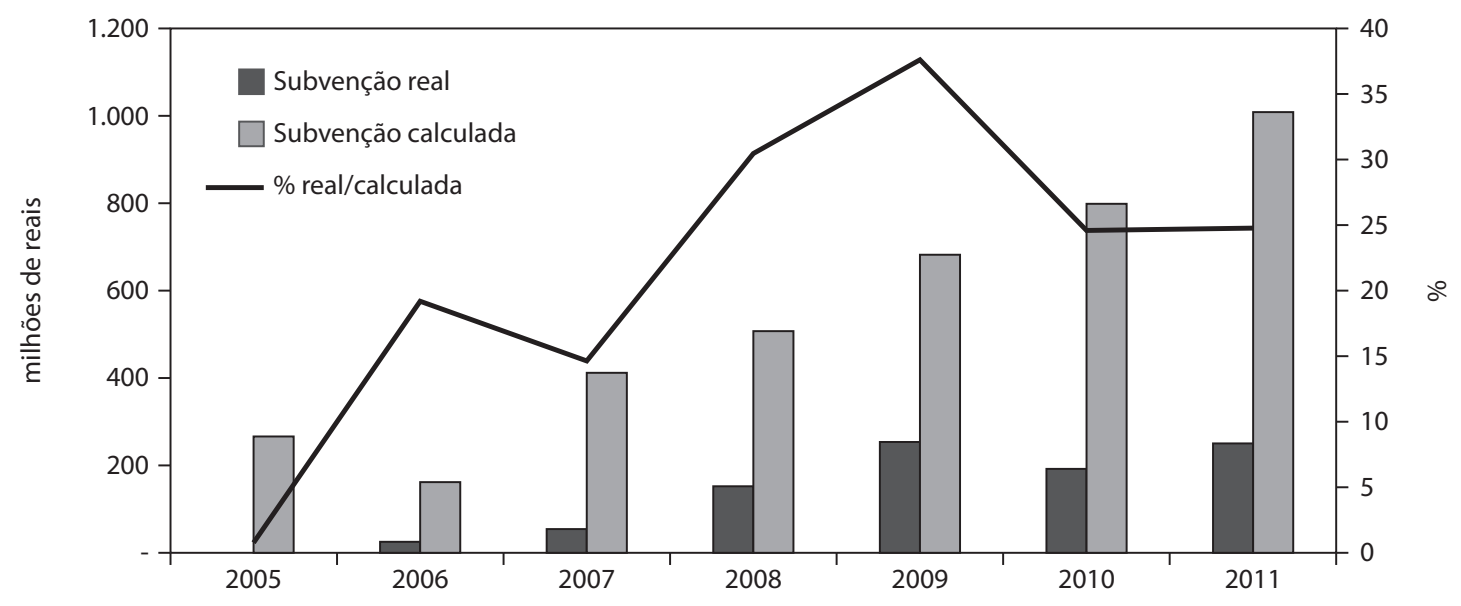

Fonte: Resultados da pesquisa. 
Tabela 5. Percentuais e valor da subvenção por cultura, tendo-se como base o valor calculado para 2011, para as dez principais culturas

\begin{tabular}{ccc}
\hline Culturas & Percentual & Subvenção (R\$) \\
\hline Soja & 37,3 & 379.505 .770 \\
Trigo & 12,6 & 128.191 .836 \\
Maçã & 11,4 & 116.273 .370 \\
Milho safrinha & 10,4 & 105.554 .072 \\
Milho & 6,5 & 65.842 .971 \\
Uva & 6,0 & 60.582 .938 \\
Arroz & 4,3 & 43.277 .571 \\
Tomate & 2,1 & 21.776 .577 \\
Algodão & 1,7 & 17.373 .275 \\
Caqui & 1,7 & 16.927 .287 \\
Outros & 6,0 & 61.248 .552 \\
Total & 100,0 & 1.016 .554 .216 \\
\hline
\end{tabular}

Fonte: Resultados da pesquisa.

atingiu quase $40 \%$. A partir desse ano, a tendência foi revertida, devido ao fato de a subvenção real ter se reduzido em comparação ao ano anterior, enquanto a subvenção calculada cresceu de 2008 para 2009. Em 2010 e 2011, esse percentual foi de aproximadamente $25 \%$.

Pelos resultados percebe-se que os valores alocados ao PSR mostram-se bem inferiores aos valores adequados para massificar o seguro rural e garantir maior estabilidade ao Sistema Nacional de Crédito Rural. Em situações normais, sem quebra de safra, o setor consegue pagar a dívida com o agente creditício, mas, quando o clima, pragas ou doenças causam reduções na produtividade agrícola, o problema da inadimplência e das perdas agrícolas afetam todas as cadeias produtivas do agronegócio, o governo e, em última instância, a própria sociedade.

Um ponto importante a se destacar é que quanto maior a taxa de prêmio e/ou o limite máximo de indenização, maior deverá ser o volume de recursos alocados ao PSR para cobrir o aumento dos prêmios. Portanto, se houver aumento do crédito de custeio, ou elevação de taxa que implique em alta no volume de prêmios ganhos, haverá maior necessidade de recursos para a subvenção. Por esse motivo, é fundamental utilizar metodologias de precificação de risco adequadas para se calcular taxas de prêmio que reflitam de forma mais precisa o risco agrícola.

\subsection{Subvenção por tipo de cultura e por estado}

As Tabelas 5 e 6 mostram o montante de recursos que seriam alocados ao PSR tendose como base a média dos resultados de 2009 e 20103. Dessa forma, nas Tabelas 5 e 6, os percentuais referentes a cada cultura e a cada estado, respectivamente, foram obtidos como uma média dos percentuais de 2009 e 2010 . Na análise, considerou-se que esses percentuais incidissem sobre o valor da subvenção total de 2011 (R\$ 1.016.554.216), resultando em valores de subvenção estimados por cultura e por estado.

A Tabela 5 mostra as subvenções por tipo de cultura. Observa-se que apenas para a soja seriam alocados quase $\mathrm{R} \$ 380$ milhões. Esse valor é aproximadamente uma vez e meia o orçamento de todo o PSR em 2011.

A Tabela 6 revela que os cinco primeiros estados, Paraná, Rio Grande do Sul, São Paulo, Santa Catarina e Mato Grosso do Sul, respondem por quase $80 \%$ de toda a subvenção. Os três estados do Sul correspondem a quase $60 \%$, com quase R\$ 590 milhões, refletindo a importância do PSR para o seguro rural na região Sul do País.

\footnotetext{
3 Até o momento do estudo, os resultados para o ano de 2011 são de 28/12/2011; porém, ainda não foram consolidadas para liberação oficial. Por isso, as médias consideradas foram apenas de 2009 e 2010.
} 
Tabela 6. Percentuais e valor da subvenção por estado, tendo-se como base o valor calculado para 2011, para os dez principais estados

\begin{tabular}{lcc}
\hline \multicolumn{1}{c}{ Estados } & Percentual & Subvenção (R\$) \\
\hline Paraná & 29,1 & 296.143 .131 \\
Rio Grande do Sul & 18,6 & 188.586 .013 \\
São Paulo & 12,1 & 123.228 .224 \\
Santa Catarina & 10,3 & 104.212 .660 \\
Mato Grosso do Sul & 8,4 & 85.729 .010 \\
Goiás & 6,8 & 69.177 .703 \\
Minas Gerais & 5,3 & 53.965 .105 \\
Mato Grosso & 4,0 & 41.151 .517 \\
Bahia & 3,9 & 39.264 .840 \\
Piauí & 0,5 & 4.687 .494 \\
Outros & 1,0 & 10.408 .521 \\
Total & 100,0 & 1.016 .554 .216 \\
\hline
\end{tabular}

Fonte: Resultados da pesquisa.

Tabela 7. Erro absoluto médio de previsão

\begin{tabular}{cc}
\hline Modelo & Valor* \\
\hline ARIMA $(1,1,0)$ & 126,92 \\
ARIMA $(0,1,1)$ & 101,96 \\
ARIMA $(1,1,1)$ & 84,99 \\
ARIMA $(2,1,0)$ & 157,73 \\
ARIMA $(2,1,1)$ & 82,22 \\
ARIMA $(2,1,2)$ & 127,24 \\
ARIMA $(0,1,2)$ & 78,86 \\
ARIMA $(1,1,2)$ & 63,93 \\
\hline
\end{tabular}

* unidade $10^{6}$.

Fonte: Resultados da pesquisa.

\subsection{Previsão dos recursos de custeio} e respectivos valores de subvenção

Com o intuito de estimar os valores subvencionados para os anos de 2012 e 2013, supondo que a totalidade do custeio estaria coberta pelo seguro, os modelos ARIMA foram utilizados para prever os valores de custeio nos anos supramencionados. Ajustou-se um conjunto de modelos à série temporal de custeio correspondente ao período de 1994 a 2011 , de tal forma que o último valor foi deixado para validação da previsão. O critério adotado para escolha de

4 Optou-se por utilizar uma série temporal menor do que aquela existente em razão do processo de estabilização econômica do País pós-plano Real. modelos foi baseado no mínimo erro absoluto médio de previsão. O melhor modelo ajustado foi o ARIMA $(1,1,2)$ sem constante (Tabela 7).

Em virtude de a série apresentar apenas 17 observações até 2010, não foi possível ajustar modelos mais complexos, com maior número de parâmetros. Ao invés disso, optou-se por modelos mais parcimoniosos, que gerassem boas previões dois passos à frente. Os testes indicaram não estacionariedade na série original, por isso, aplicou-se uma diferença, resultando em série estacionária. A checagem dos ruídos confere um padrão de ruído branco. As previsões do custeio para 2012 e 2013, utilizando o modelo ARIMA $(1,1,2)$, encontram-se na Tabela 8 , bem como seu intervalo de confiança superior e inferior. 
Tabela 8. Previsões para os anos de 2012 e 2013, com os intervalos superior e inferior ao nível de $95 \%$

\begin{tabular}{ccc}
\hline Previsão & Interv. Superior & Interv. Inferior \\
\hline 31.847 .964 .225 & 29.196 .300 .974 & 34.499 .627 .475 \\
33.217 .136 .970 & 27.315 .440 .954 & 39.118 .832 .985 \\
\hline
\end{tabular}

Fonte: Resultados da pesquisa.

Figura 6. Previsões do crédito de custeio para os anos de 2012 e 2013, com os intervalos de confiança ao nível de $95 \%$

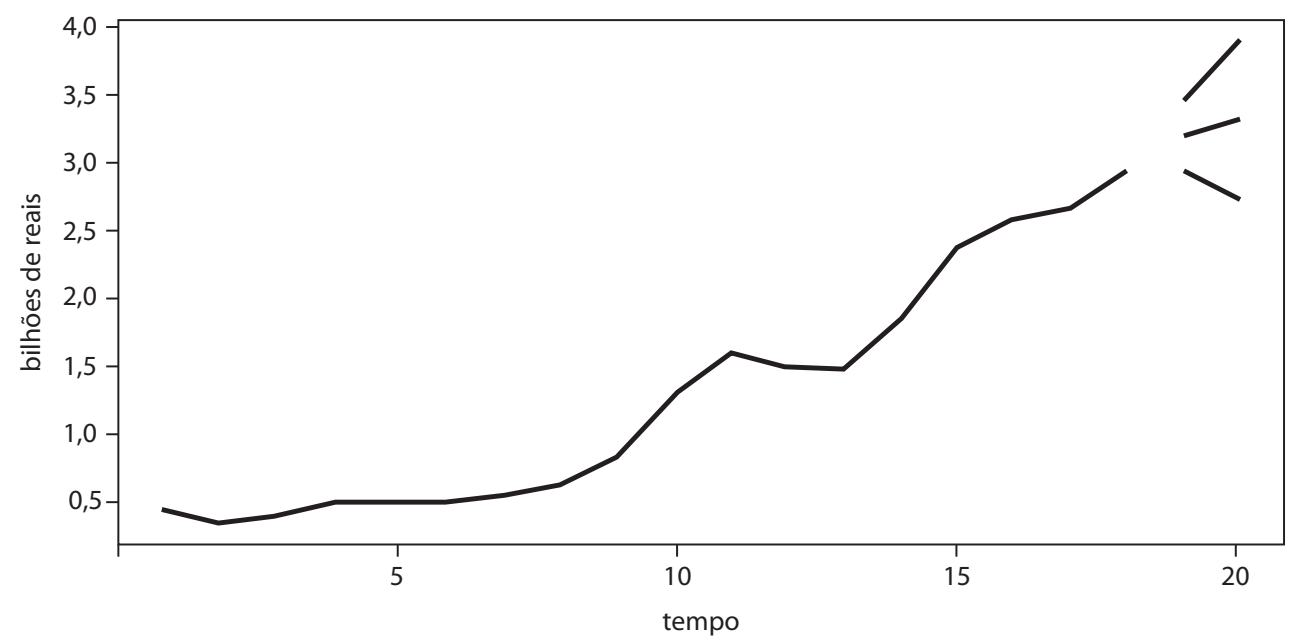

Fonte: Resultados da pesquisa.

A Figura 6 mostra a série de custeio de 1994 a 2011 e as previsões para os anos de 2012 e 2013 com o intervalo de confiança ao nível de 95\%. Nota-se que as previsões seguem a tendência de aumento do custeio.

Para o cálculo do valor médio do prêmio para 2012 e 2013, utilizou-se como base a taxa média de 2005 a 2011, que foi de aproximadamente $5 \%$. Dessa forma, utilizando-se as previsões e supondo-se uma variação da taxa média de prêmio em um ponto percentual para cima e para baixo, os respectivos valores médios do prêmio são dados pela multiplicação da taxa média pelos valores previstos de custeio (Tabela 9).

Pela tabela, nota-se que se a taxa média se situar ao redor de 4\%, em 2012, o valor arrecadado do prêmio será de aproximadamente R\$ 1,3 bilhão.

Uma vez calculado o valor médio do prêmio, o próximo passo consiste em se determinar o valor médio da subvenção. O percentual médio de subvenção (subvenção total / prêmio total),

Tabela 9. Valor médio do prêmio calculado com base na taxa média de prêmio para os anos de 2012 e 2013

\begin{tabular}{cccc}
\hline Ano & Taxa média de prêmio & Custeio previsto & Valor médio do prêmio \\
\hline \multirow{2}{*}{2012} & $4,0 \%$ & 31.847 .964 .225 & 1.273 .918 .569 \\
& $5,0 \%$ & 31.847 .964 .225 & 1.592 .398 .211 \\
& $6,0 \%$ & 31.847 .964 .225 & 1.910 .877 .854 \\
\hline \multirow{2}{*}{2013} & $4,0 \%$ & 33.217 .136 .970 & 1.328 .685 .479 \\
& $5,0 \%$ & 33.217 .136 .970 & 1.660 .856 .849 \\
\hline
\end{tabular}

Fonte: Resultados da pesquisa. 
Tabela 10. Percentual médio de subvenção e valores médios de subvenção para os anos de 2012 e 2013

\begin{tabular}{ccc}
\hline & \% Médio de subvenção & Valor médio de subvenção \\
\hline \multirow{2}{*}{2012} & $45 \%$ & 573.263 .356 \\
& $50 \%$ & 796.199 .106 \\
& $55 \%$ & 1.050 .982 .819 \\
\hline \multirow{2}{*}{2013} & $45 \%$ & 597.908 .465 \\
& $50 \%$ & 830.428 .424 \\
\hline
\end{tabular}

Fonte: Resultados da pesquisa.

desde 2005, situou-se em torno de 50\%, ou seja, para um total em prêmios de R $\$ 100$ mil, o total coberto pela subvenção é, em média, igual a R\$ 50 mil. Para o cálculo do valor da subvenção, considerou-se, além do percentual médio de $50 \%$ uma variação de 5 pontos percentuais para cima e para baixo (55\% e $45 \%)$ (Tabela 10$)$

Em seguida, cada valor médio do prêmio, obtido pela multiplicação da taxa média pelo custeio previsto, foi multiplicado pelo percentual médio de subvenção para calcular o valor médio de subvenção (Tabela 10). Dessa forma, multiplicando-se $45 \%$ por $\mathrm{R} \$ 1.273 .918 .569$, obtêm-se a subvenção média de R 573 milhões, para 2012, para o percentual médio de $45 \%$. E, assim por diante, para a relação taxa média de prêmio / percentual médio de subvenção: $4 \%$ / $45 \%$; $5 \% / 50 \%$; e $6 \% / 55 \%$.

Os resultados mostram que, para um percentual médio de subvenção de $45 \%$, os valores alocados ao PSR deveriam ser, para os anos de 2012 e 2013, respectivamente, $R \$ 573,3$ milhões e R\$ 597,9 milhões. Ao nível de 50\%, respectivamente, $\mathrm{R} \$ 796,2$ milhões e $\mathrm{R} \$ 830,4$ milhões. E pouco mais de $\mathrm{R} \$ 1$ bilhão para um percentual de $55 \%$.

\subsection{Problemas de contingenciamento no orçamento do PSR}

Até 2008, os recursos disponibilizados ao PSR foram suficientes para cobrir a demanda. Nesse ano, dos R\$ 160 milhões disponibilizados ao Programa, foram gastos efetivamente R \$ 157,5 milhões. No entanto, essa situação se inverteu em 2009, quando a demanda excedeu o total disponibilizado pelo governo em R $\$ 90$ milhões. Ou seja, o governo ficou com saldo devedor junto às seguradoras.

Em dezembro de 2009, o governo aprovou um projeto de lei com recursos extras para recompor o orçamento e zerar a dívida. Porém, de acordo com as normas do PSR, os recursos da subvenção devem ser usados no mesmo ano da liberação dos recursos. Como não houve uso nesse mesmo ano, as seguradoras deixaram de receber os recursos.

Na época, o governo sinalizou ao mercado que iria utilizar parte do orçamento de 2010, da ordem de R\$238 milhões, como pagamento dos R\$ 90 milhões de 2009. Esse fato gerou grande insatisfação no mercado. Além de o governo não ter aumentado os recursos para a subvenção em 2010, conforme o Plano Trienal, o novo orçamento ainda seria reduzido em R\$ 90 milhões. Mas, em maio de 2010, o governo sancionou a Lei n. 12.241 aprovando o crédito suplementar de R\$ 90 milhões para recompor o orçamento do ano.

Apesar disso, o problema voltou a ocorrer no segundo semestre de 2010. Naquele ano, dos R\$ 198 milhões gastos com o PSR, o governo havia repassado às seguradoras apenas $\mathrm{R} \$ 35$ milhões até o final de 2010, transferindo para 2011 um saldo devedor de $\mathrm{R} \$ 163$ milhões.

Em 2011, os recursos do saldo devedor foram empenhados e liberados pelo Ministério da Fazenda. Por intermédio da Lei Orçamentária Anual, foram alocados ao PSR, em 2011, recursos da ordem de R\$ 406 milhões, mas, devido ao contingenciamento, apenas $\mathrm{R} \$ 253$ milhões foram liberados. 
Em 2012 foram aprovados na LOA recursos da ordem de R\$ 170 milhões, que foram complementados com recursos do próprio Mapa. Portanto, em 2012, o PSR disponibilizará R\$ 270 milhões para a contratação do seguro rural nas safras de verão e inverno 2012/13. Esse valor é um pouco superior ao disponibilizado em 2011, mas insuficiente para atender a crescente demanda pelo seguro.

Observa-se, pelos fatos ocorridos nos últimos três anos, que existe grande incerteza no mercado com relação aos recursos que serão alocados ao PSR. Apesar de o Plano Trienal estabelecer estimativas de aportes de recursos, o que se observa é que o orçamento do PSR enfrenta contingenciamentos arbitrários. Essa insegurança inviabiliza qualquer planejamento das empresas do mercado segurador e, inclusive, afeta as decisões do próprio Mapa, que não consegue definir os rumos do PSR.

\section{Conclusão}

O PSR é fundamental para a massificação do seguro rural. A experiência internacional mostra que a participação do governo nesse mercado é importante na medida em que reduz o prêmio pago pelos produtores e, em alguns casos, o governo subsidia até o custo operacional e administrativo das seguradoras, como no caso do seguro agrícola norte-americano.

Existem vários modelos de parcerias público-privadas no seguro agrícola, mas em todos os casos existe o comprometimento e apoio efetivo do governo. No Brasil, apesar de o Plano Trienal estimar um valor orçamentário para cada ano, os valores empenhados ainda estão longe do patamar adequado para um seguro agrícola abrangente; além disso, não existe regra clara com relação ao orçamento que será disponibilizado ao mercado.

Nesse contexto, o estudo contribui para melhorar o PSR, na medida em que sinaliza as metas orçamentárias do Programa, sob a hipótese de que todo o crédito rural de custeio para as lavouras será segurado. Em outras palavras, quanto o governo deveria gastar se quisesse garantir todo o crédito de custeio? Sob essa hipótese, seriam necessários pouco mais de $\mathrm{R} \$$ 1 bilhão de subvenção, em 2011, para segurar aproximadamente $\mathrm{R} \$ 29$ bilhões em custeio de lavouras. Ressalta-se que, quanto maior a taxa de prêmio praticada no mercado e/ou maior o volume de custeio, maior será o prêmio total e, consequentemente, maior deverá ser o montante de recurso alocado ao PSR.

Em 2012 e 2013, deveriam ser alocados entre $\mathrm{R} \$ 500$ milhões e pouco mais de $\mathrm{R} \$ 1$ bilhão, dependendo do percentual de subvenção. Assim, considerando-se o mesmo percentual de 2011 (quase 55\%), o orçamento para 2012 e 2013 deveria ser aproximadamente igual a $\mathrm{R} \$ 1$ bilhão. Com essa meta definida, o planejamento a médio e longo prazo torna-se mais eficiente, com possibilidade de se alocar recursos que sejam "blindados", ou seja, que sejam destinados exclusivamente ao PSR.

A análise levou em conta apenas o crédito governamental de custeio para lavouras enquandrado no Sistema Nacional de Crédito Rural (SNCR). Porém, o seguro agrícola pode ser customizado para garantir outras formas de financiamento de custeio, por exemplo, aquelas provenientes do mercado privado (novos títulos do agronegócio), ou mesmo outros produtos de seguro que possam cobrir não apenas o valor da produção agrícola mas também o faturamento da atividade. Nesses casos, o orçamento do PSR deverá ser bem superior ao calculado nesse estudo.

Apesar das dificuldades de se desenvolver um seguro rural abrangente, nota-se que existe grande interesse por parte dos órgãos representativos do setor agropecuário em ampliar o seguro rural, a fim de proteger produtores contra as intempéries climáticas. Ademais, o setor de seguros também tem se movimentado, melhorando e lançando novos produtos, alterando níveis de cobertura, adequando processos de regulação de sinistros e investindo em divulgação do seguro rural.

Apesar disso, os problemas do PSR implicam em sinais negativos ao mercado, que, em 
resposta, retrai investimentos no ramo de seguro rural, aguardando uma resposta mais confiável do governo. Além disso, existe a questão da regulamentação do Fundo de Catástrofe, sancionada em 2010, mas ainda não regulamentada. Se existe tamanha dificuldade orçamentária no PSR, o que dizer da regulamentação do Fundo, que deve receber $\mathrm{R} \$ 4$ bilhões?

Por fim, a expectativa é que o governo mantenha sua credibilidade, honrando e ampliando o investimento em políticas voltadas ao seguro rural, visto que existe uma demanda contida e empresas preparadas para garantir as indenizações nas frustrações de safra. Falta, ainda, um fator fundamental ao mercado de seguro agrícola: a vontade e a determinação do governo em tornar o PSR uma verdadeira política agrícola para gestão de riscos baseada no seguro rural privado.

\section{Referências bibliográficas}

AGROSEGURO. http://www.agroseguro.es/principal1. html (2012)

ALMEIDA, S. W. Massificação das operações do seguro rural: o grande desafio brasileiro. Revista de Política Agrícola, n. 4, p. 21-26, 2007.

BACEN. http://www.bcb.gov.br/?RELRURAL (2012)

BOX, G.E.P., JENKIS, G.M. e REINSEL, G.C. Time Series Analysis: Forecasting and Control. São Francisco: Wiley, 2008.
CRYER, J.D. e CHAN, K.S. Time series analysis with applications in R. Iowa: Springer, 2008.

DIKEY, D.A. e FULLER, W.A. Distribution of the estimator for auto-regressive time series with a unit root. Journal of the American Statistical Association, v. 74, n. 366, p. 427-431, 1979.

DIKEY, D.A. e FULLER, W.A. Likelihood ratio statistics for autoregressive time series with a unit root. Econometrica, v. 49, n. 4, p. 1057-1072, 1981.

FULLER, W.A. Introduction to statistical time series. Nova Iorque: John Wiley \& Sons, 1976.

LJUNG, G.M. e BOX, G.E.P. On a Measure of a Lack of Fit in Time Series Models. Biometrika, v. 65, n. 2, p. 297-303, 1978.

MAPA. http://www.agricultura.gov.br/ (2012).

OZAKI, V.A. Viabilidade financeira do seguro agrícola: aplicações da análise espectral para a quantificação dos prejuízos agrícolas e de modelos atuariais para a precificação do risco. Piracicaba, 2012. 98p. Tese (LivreDocência) - Escola Superior de Agricultura "Luiz de Queiroz", Universidade de São Paulo.

OZAKI, V.A. Em busca de um novo paradigma para o seguro rural no Brasil. Revista de Economia e Sociologia Rural, v. 46, p. 97-119, 2008.

$\mathrm{R}$ Development Core Team. R: A Language and Environment for Statistical Computing, R Foundation for Statistical Computing, ISBN 3-900051-07-0, 2012.

RAMOS, R.C. O seguro rural no Brasil: origem, evolução e proposições para aperfeiçoamento. Informações Econômicas, v. 39, n. 3, 2009.

USDA/RMA. http://www.rma.usda.gov/ (2012). 